\title{
Aplicação de fluxo contínuo como contribuição no aumento da produtividade e diminuição do lead time de uma Indústria Metalúrgica
}

Paulo André Miranda Lima paulo.brasnet01@gmail.com

Faculdade Farias Brito (FFB), Fortaleza, $\mathrm{CE}$, Brasil

\section{Mauricio Johnny Loos} mauricioloos@hotmail.com

Faculdade Farias Brito (FFB), Fortaleza, FE, Brasil

\author{
RESUMO
}

Muito se fala sobre a baixa produtividade do Brasil em relação a países estrangeiros e, no tocante as organizações, especificamente no setor industrial, esse cenário é bem mais perceptível. Muitas empresas, para conseguirem otimizar seus resultados, recorrem à implantação de ferramentas da Filosofia Lean, a qual busca incessantemente pela redução de desperdícios, e mostra que o envolvimento das pessoas é um dos pontos cruciais do sucesso. Nesse artigo demonstra-se a aplicação de técnicas Lean e seus resultados práticos e efetivos numa linha de manufatura industrial, onde o objetivo é criar um ambiente produtivo favorável a desenvolver o conceito de Fluxo Contínuo, desencadeando como resultado, aumento de produtividade e diminuição do lead time. Os resultados apurados nessa implantação mostraram-se muito exitosos, com grande melhoria ergonômica para os colaboradores, adoção de nova filosofia de trabalho em série, ganhos em produtividade, eliminação de desperdícios, diminuição do tempo de atravessamento do produto pelo fluxo de valor e baixo custo de investimento.
\end{abstract}

PALAVRAS-CHAVE: Produtividade. Fluxo contínuo. Produção enxuta. Valor agregado. 


\section{INTRODUÇÃO}

A crise econômica que atinge o país revela dados impressionantes, pois de acordo com um levantamento, ilustrado pela figura 1, feito em 2016 pela empresa Neoway, em parceria com a GS\&MD, no ano de 2015, a taxa de mortalidade das empresas brasileiras quase triplicou quando comparado com o mesmo período de 2014 , que foi de $3,36 \%$. Esse número também se mostra o maior desde 2009, que foi de $2,62 \%$.

Junta-se, à dificuldade anteriormente exposta, um problema antigo, persistente e extremamente comum nas organizações de manufatura nacionais: a baixa produtividade. Esse indicador, é uma variável que corrói a competitividade do business nacional e impede a evolução no incremento do Produto Interno Bruto (PIB), assim como também emperra o desenvolvimento de um ciclo virtuoso, que levaria ao aumento da contratação de mão de obra.

Figura 1 - Comparativo de Produtividade

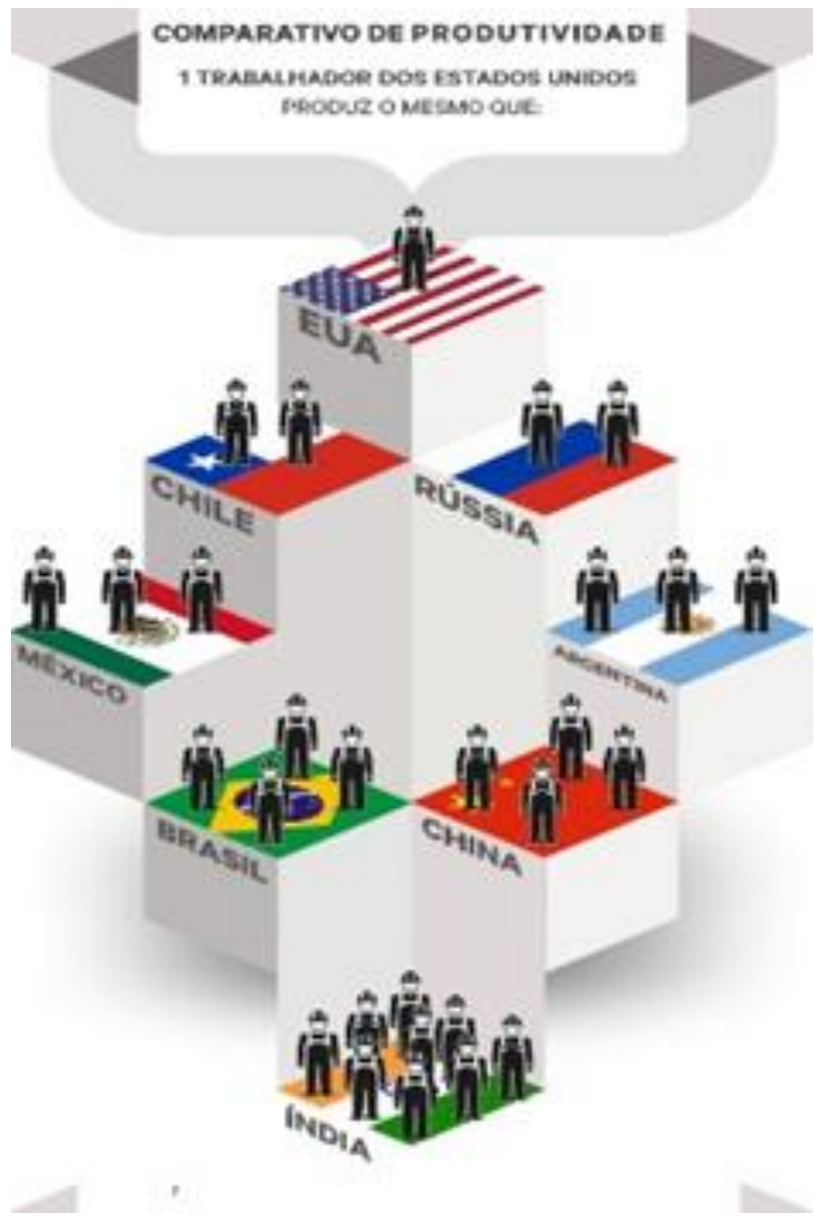

Fonte: Adaptado de The Conference Board Total Economy Database (2015).

Segundo Roberto Ellery, professor da Universidade de Brasília (UnB), em seu estudo constatou que em pouco mais de quatro décadas, o Brasil andou na contramão da eficiência produtiva quando comparado com países concorrentes. Entre 1970 e 2011, a Produtividade Total dos Fatores (PTF), composta pelos indicadores: capital, trabalho e capital humano, nos Estados Unidos registraram um crescimento de $38 \%$, enquanto que no Brasil a PTF caiu cerca de $10 \%$. 
Pela importância do assunto, justifica-se abordar o tópico produtividade, utilizando um estudo de caso, utilizando ferramentas de produção enxuta.

Esse artigo foca na descrição da aplicação da metodologia de fluxo contínuo em uma empresa metalúrgica, apoiado por outras ferramentas que compõe a filosofia do Lean Manufacturing e que completam ações para contribuir no aumento de produtividade em uma organização. Para cumprir seus objetivos, o trabalho primeiramente estabelece o referencial teórico, seguido pelos procedimentos metodológicos adotados, resultados empíricos e, finalmente, suas conclusões.

\section{REVISÃO DA LITERATURA}

Esse seguimento do artigo explana sobre os conteúdos teóricos que embasam o estudo das ferramentas da filosofia de trabalho Lean Manufacturing. $\mathrm{O}$ foco da contextualização são as metodologias que contribuem para o objetivo final, ou seja, o trabalho em fluxo contínuo. Para tratar da ferramenta fluxo contínuo, serão sintetizados alguns conteúdos que possuem forte aderência com essa técnica, tais como: conceitos de Fluxo de Valor e Mapeamento de Fluxo de Valor, identificação de Valor Agregado, conceitos básicos de Layout (Arranjo físico do processo) e avaliação de Tempos e Movimentos.

\section{FLUXO DE VALOR E SEU MAPEAMENTO}

De acordo com a interpretação de Rother e Shook (1999), "Fluxo de Valor" é entendido como ações que transportam o produto por todas as etapas que compõem a cadeia do processo, ou seja, é todo fluxo de produção, transformando desde a matéria-prima até a entrega ao consumidor.

O Mapeamento do Fluxo de Valor (MFV) é uma ferramenta do Lean que trata de enxergar não só o fluxo de material mais também o fluxo de informação. 0 objetivo é identificar, melhorar e implementar um fluxo agregador de valor, eliminando as fontes dos desperdícios atuais e também auxiliar no desenho das estratégias para o estado futuro.

Rother e Shook (2008), tem como ponto de vista que o Mapeamento do Fluxo de Valor (MFV), traz como vantagem o fato de se aplicar ferramentas e técnicas de Produção Enxuta de forma integrada e não isolada. Diz ainda que o mapeamento forma a base de um plano estratégico de implantação e que seu formato permite enxergar a relação entre fluxo de material e fluxo de informação, característica rara e incomum em muitas ferramentas de mapeamento. A figura 2 apresenta um gráfico de Mapeamento do Fluxo de Valor (MFV). 
Figura 2 - Gráfico de Mapeamento do Fluxo de Valor-MFV

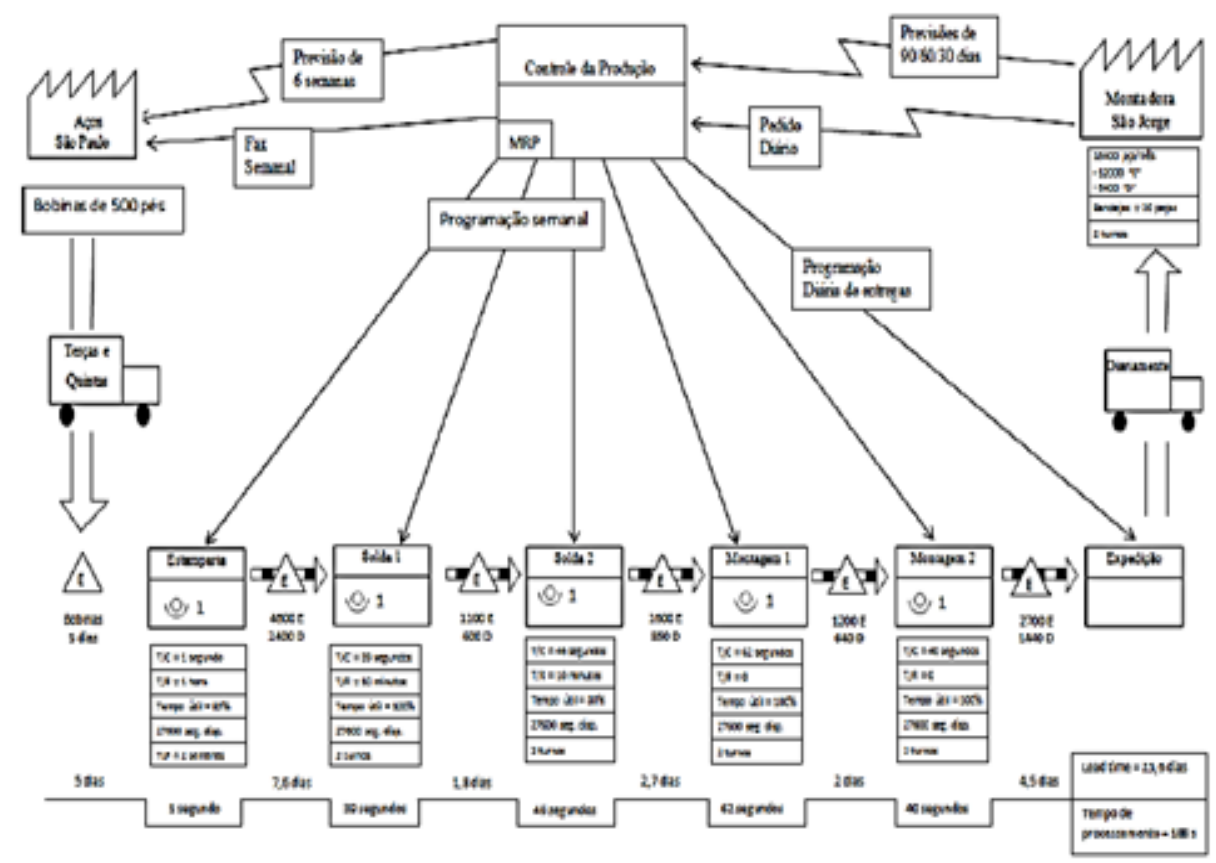

Fonte: Mike Rother \& John Shook (2008).

Para, Ferro (2003) o mapeamento é uma ferramenta que possibilita enxergar agregação de valor nas atividades de forma horizontal, o que rompe a forma tradicional de ver o processo de maneira isolada, visualizando somente funções ou departamentos. Ferro (2003) diz ainda que o Mapeamento de Fluxo de Valor foca também nas atividades, ações e conexões de maneira a criar valor e fazê-lo fluir, em toda cadeia, desde os fornecedores até o cliente final.

\section{ENXERGANDO "VALORES" NOS ELEMENTOS DE TRABALHO}

Antes de avançar no assunto, deve-se enxergar valores contidos nos elementos de trabalho e entender do que se trata valor para a filosofia de trabalho Lean.

Valor na cultura Lean é toda atividade que gera percepção de importância para o cliente, ou seja, o cliente se torna disposto a pagar, por perceber que aquele produto ou serviço vai satisfazer sua necessidade. Dessa forma, para desenvolver produtos ou serviços, onde envolvam o manuseio humano, a melhor situação será sempre adicionar atividades que gerem valor agregado, pois, o contrário disso é desperdício. A figura 3 ilustra sobre os tipos de valores agregados e desperdícios. 
Figura 3 - Representação dos valores para elementos de trabalho

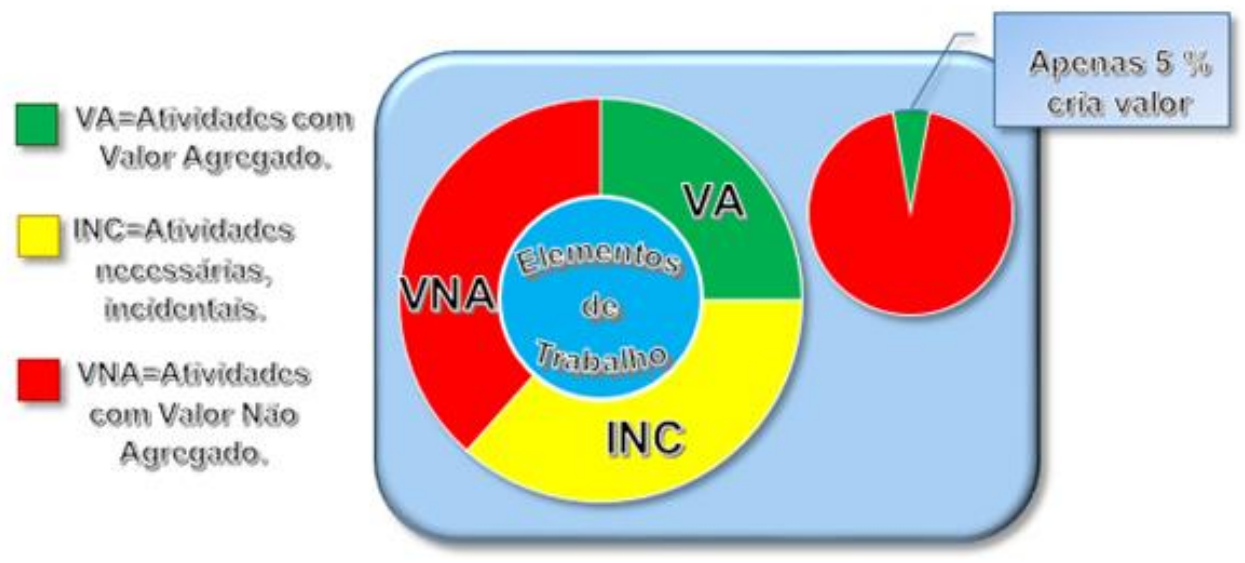

Fonte: Autoria própria (2016).

Mas o que é desperdício? Para a filosofia Lean, desperdício, descrito em japonês com o termo Muda, é toda atividade que absorve recursos da organização e não gera valor percebido pelo cliente. Há ainda, uma subdivisão classificando o desperdício como tipo 1, ou seja, o que não cria valor, porém, é uma ação necessariamente coexistente, como por exemplo: inspecionar peças durante o processo como foco de garantia da qualidade. Existe ainda o desperdício do tipo 2, que não agrega nenhum tipo de valor ao cliente e deve ser descartado o quanto antes, pois afeta de forma evidente. Para essa situação, pode-se citar, como exemplo, o excesso de movimentação por conta de mau posicionamento de materiais a serem transportados.

Shingo (1996), Ohno (996) e Ghinato (1996) definem que existem 7 desperdícios que não criam valor ao cliente, sendo eles: Superprodução, Espera, Excesso de Transporte, Processamento Desnecessário, Excesso de Estoque, Excesso de Movimento, Defeitos e Retrabalhos.

Mika (2001), acrescenta mais desperdícios e cita:

- Baixa ou não utilização da capacidade intelectual do ser humano;

- Uso de indicadores mal implantados;

- Mal utilização de computadores.

Para Peter Hines e David Taylor (2000), em empresas de manufatura, o percentual de agregação de valor, se comparado com o total da atividade, não passa de $5 \%$, ou seja, nos ciclos, apenas $5 \%$ dos elementos de trabalho criam valor agregado aos produtos.

Em uma de suas pesquisas, o consultor estadunidense Michael L. George (2002), pioneiro na implantação do processo de Seis Sigma nos Estados Unidos, descreve que em organizações tradicionais seus processos de manufatura, especificamente linha de montagem, a agregação de valor não passa de $15 \%$, já em manufaturas que adotaram preceitos e técnicas para gestão de processos produtivos de padrão mundial, conhecido internacionalmente por World Class Manufacturing (WCM), aplicados na linha de montagem em seus processos possuem eficiência na agregação de valor superior a 35\%, conforme, demonstrado pela figura 4. 
Figura 4 - Gráfico comparativo entre agregação de valor, nos diferentes sistemas de organização produtiva

\begin{tabular}{|c|c|c|}
\hline TIPOS DEPROCESOS & 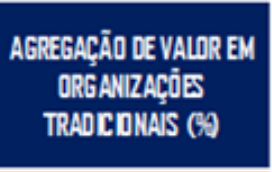 & $\begin{array}{l}\text { AGREGACC̄Ã DE VALDR EM } \\
\text { ORGANIZAÇĊES COM } \\
\text { PROCESSODE CLASSE } \\
\text { MJNDIAL (Y9) }\end{array}$ \\
\hline LECÂNICOS & 1 & 20 \\
\hline FABRICACÃD & 10 & 25 \\
\hline AOMNSTRATIVOS & 10 & 50 \\
\hline MONTAEEM & 15 & 35 \\
\hline MANUFATURA COVTINUA & 30 & 80 \\
\hline
\end{tabular}

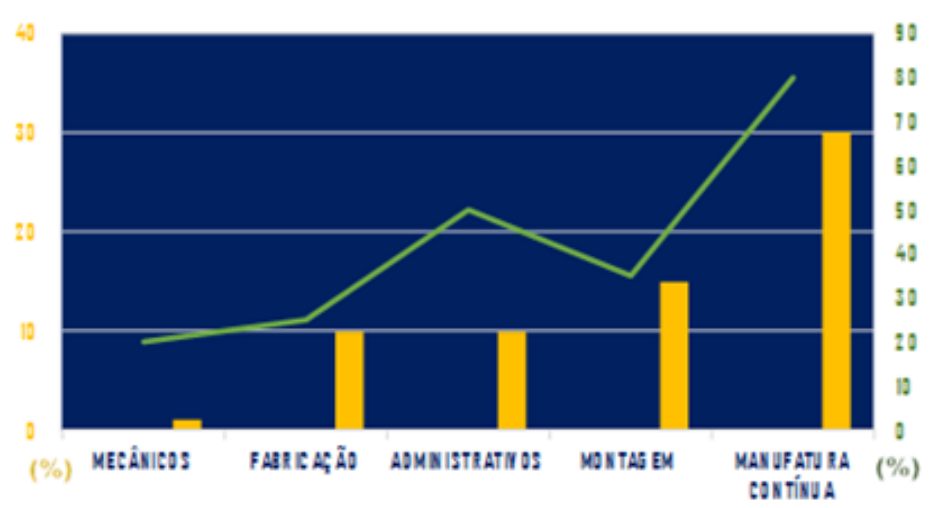

Fonte: Autoria própria (2016).

Mesmo em processos maduros, deve-se sempre questionar se o cliente continua disposto a pagar por aquelas atividades inseridas no processo de elaboração. Se na grande maioria das atividades, tem-se desperdícios, é bem-vinda a atitude de se aplicar melhoria contínua nos processos sempre, eliminando o que não agrega valor e racionalizando atividades que possuem valor agregado. Descartar grandes quantidades dos desperdícios potencializa o desempenho das organizações por satisfazer o cliente.

\title{
LAYOUT (ARRANJO FÍSICO DE PROCESSO)
}

Rocha (1995), cita a Internacional Labour Office, que define layout como sendo:

\begin{abstract}
“...a posição relativa dos departamentos, seções ou escritórios dentro do conjunto de uma fábrica, oficina ou área de trabalho; das máquinas, dos pontos de armazenamento e do trabalho manual ou intelectual dentro de cada departamento ou seção; dos meios de suprimento e acesso às áreas de armazenamento e de serviços, tudo relacionado dentro do fluxo do trabalho".
\end{abstract}

Um layout mal ordenado, transforma um ambiente de manufatura em infraestrutura pouco produtiva e isso é potencializado quando as pessoas dependem desse ambiente para desenvolverem seu trabalho.

Já Cury (2006), interpreta layout, como sendo: “... arranjo dos diversos postos de trabalho nos espaços existentes na organização, envolvendo, além da 
preocupação de melhor adaptar as pessoas ao ambiente de trabalho, segundo a natureza da atividade desempenhada, a arrumação dos móveis, máquinas, equipamentos e matérias-primas".

Petrônio Garcia Martins (2009), cita os principais tipos de layout de manufatura, que são:

\section{- Layout por processo ou funcional (Job Shop)}

Todos os processos, operações e maquinários do mesmo tipo, necessários a desenvolverem os produtos se concentram na mesma área. A flexibilidade desse tipo de organização produtiva, permite que o material seja direcionado para os distintos processos, onde, também é possível trabalhar em lotes de tamanhos pequenos e médios em fluxos de manufaturas longos. A possibilidade de causar monotonia no operador nesse formato de fluxo produtivo é menor do que em outros layouts, por exigir dinamismo e menos repetitividade. A figura 5 ilustra o layout do tipo funcional.

Figura 5 - Exemplo de layout por processo ou funcional

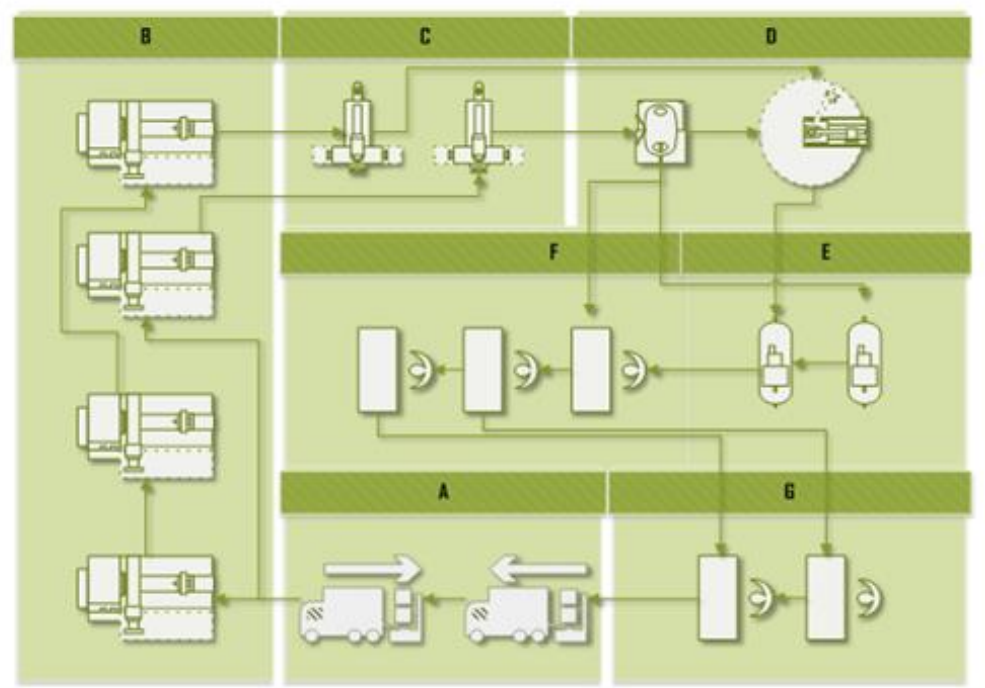

Fonte: Autoria própria (2016).

\section{- Layout em linha ou por Produto}

As estações de trabalho ou os maquinários são dispostos em sequência de acordo com as operações necessárias à fabricação do produto, como mostra a figura 6 , por isso, o fluxo produtivo proporciona poucas ou nenhuma alternativa de rota produtiva. Também, sua baixa opção para sequenciar a produção, permite grande velocidade de manufatura e fabricação em grandes quantidades. Já, para o operador pode gerar estresse e monotonia. 
Figura 6 - Exemplo de layout em linha

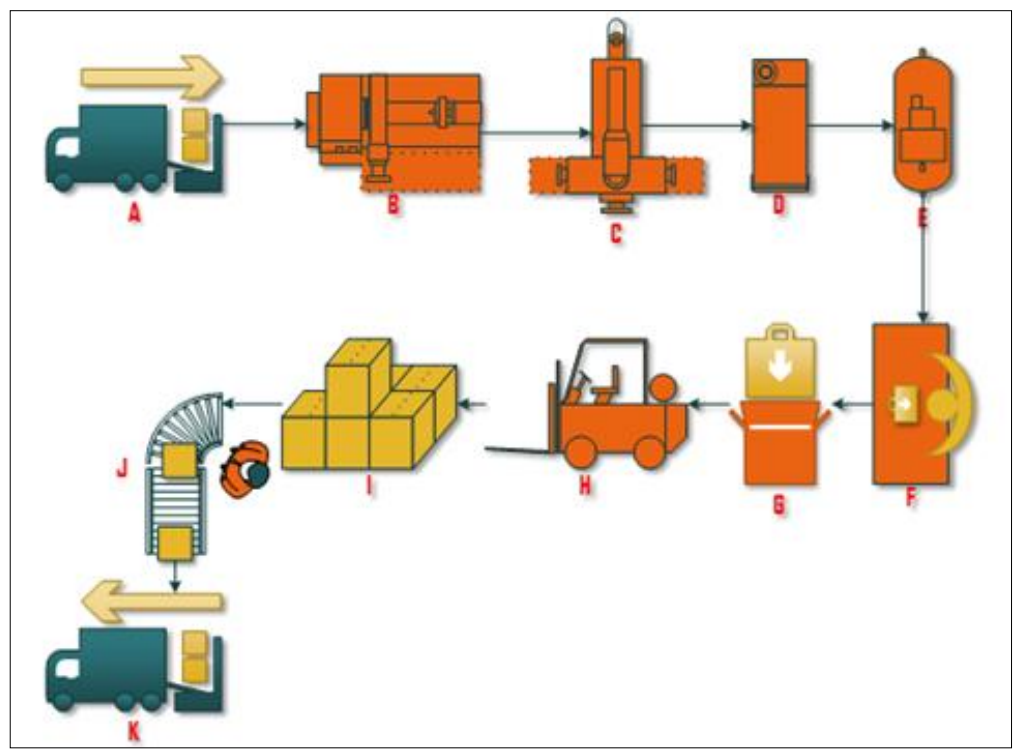

Fonte: Autoria própria (2016).

\section{- Layout celular}

O layout celular ou célula de manufatura aglutina em um mesmo espaço, todos os maquinários e processos necessários para levar o produto por todo o fluxo de valor, até a sua conclusão por completo. Conforme, mostra a figura 7, o arranjo dos maquinários, processos e pessoas, é disposto de maneira a fazer o produto seguir para os processos necessários a sua formação. Também, esse tipo de arranjo produtivo permite certa flexibilidade relativa ao porte de lotes por cada produto, o que permite um aumento na produtividade da célula. Outra característica favorável a esse tipo de layout é a diminuição de estoque e deslocamento do material, além da diminuição do desgaste físico, o que favorece a ergonomia, a grande concentração de variados tipos de processo em um mesmo ambiente, e possibilita maior dinamismo e uma menor monotonia.

Figura 7 - Exemplo de layout celular

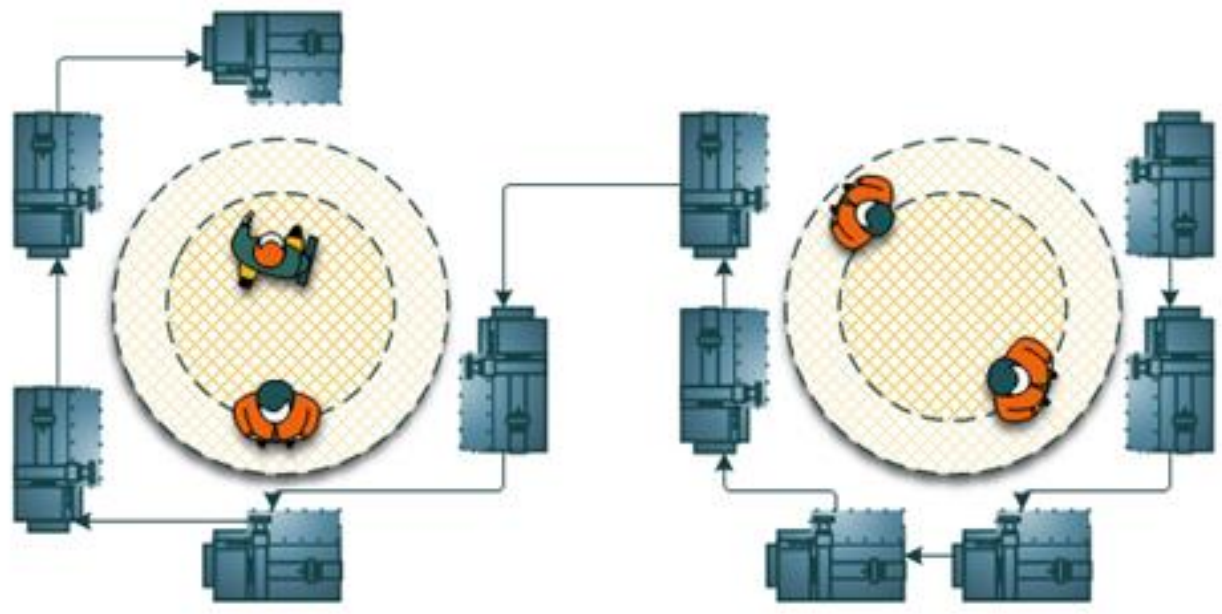


Fonte: Autoria própria (2016).

\section{- Layout por posição fixa ou posicional}

No layout por posição fixa ou posicional, o produto a ser construído fica estacionário e o processo acontece em sua volta. De acordo como mostrado na figura 8, o maquinário e as pessoas se deslocam em direção ao encontro com o projeto a ser executado.

É um arranjo produtivo indicado para produtos únicos, geralmente de grande proporção, com atuação específica, feitos sob encomenda.

Figura 8 - Exemplo de layout por posição fixa

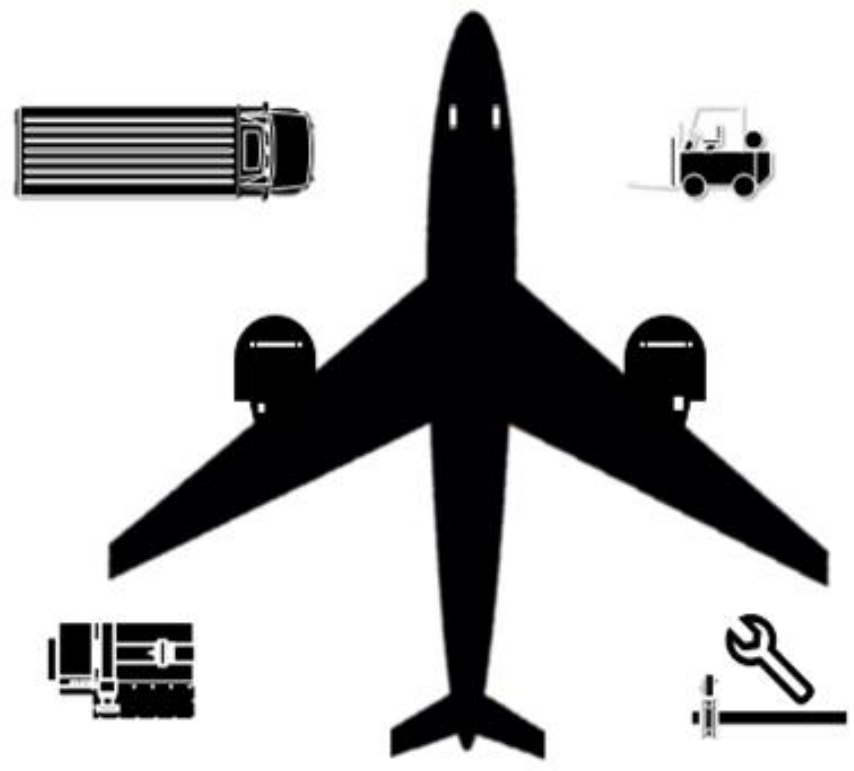

Fonte: Autoria própria (2016).

\section{- Layout combinado ou misto}

É um arranjo produtivo que se aproveita das vantagens de se unir as características dos layouts de linha de montagem e funcional, como mostra a figura 9.

Figura 9 - Exemplo de layout combinado

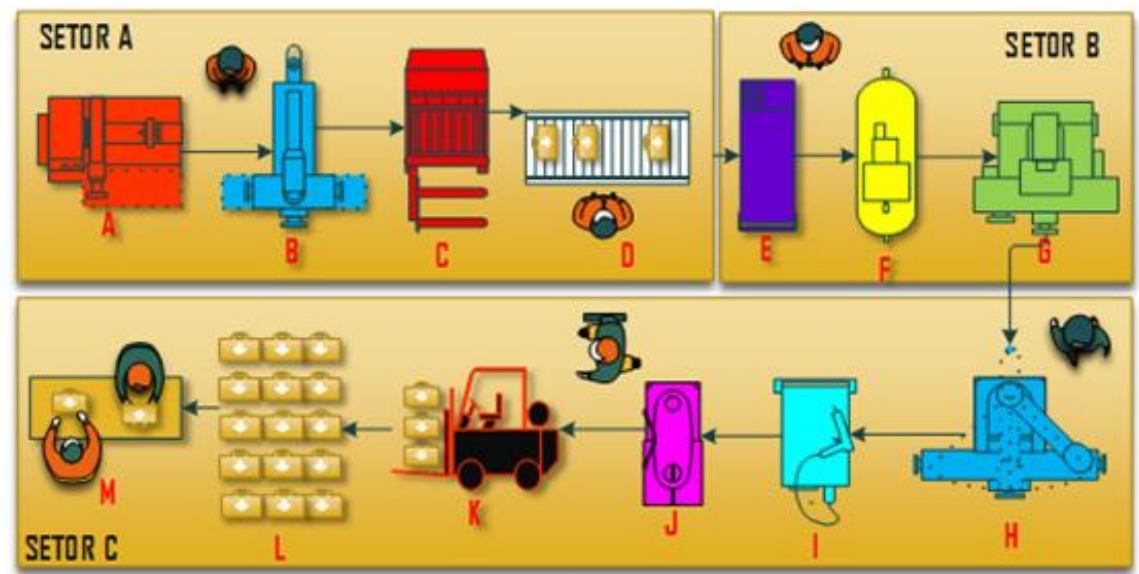


Fonte: Autoria própria (2016).

\section{AVALIAÇÃO DE TEMPOS E MOVIMENTOS}

Para Martins (2009), a contribuição do engenheiro americano Frederick Taylor com a aplicação do estudo de cronometragem nas linhas de montagem é uma importante contribuição que embasou a Administração Científica e influenciou o modo de enxergar o comportamento de eficiência individual do trabalhador.

Esse mesmo autor relata ainda que o estudo dos tempos padrões é importante para determinar metas padrões e dar base também para cálculos de custos industriais.

Turner (1993), coloca que Taylor, já no início do século XX, por meio de seu estudo de tempos padrões, incluía em suas análises tolerâncias, considerando os descansos e as pausas.

De acordo com Slack (2008), existem algumas etapas a serem seguidas, antes de marcar e acompanhar os tempos das atividades, tais como: durante os vários ciclos acompanhados, deve-se observar e medir os tempos para cada elemento das atividades; trabalhar com tempos padrões normalizados ou ajustados; elaborar o tempo médio em cima dos tempos ajustados, para definir o tempo base.

\section{O CONCEITO E A RELEVÂNCIA DO FLUXO CONTÍNUO NUM SISTEMA DE PRODUÇÃO POR DEPARTAMENTOS}

Baseado no Léxico Lean, conceitua-se fluxo contínuo como o movimento de um item por vez, chamado pela filosofia Lean como: one-piece-flow ou segundo o próprio Léxico Lean como sendo o movimento de um pequeno lote de itens no decorrer de uma longa série de etapas de processamento, feito de forma contínua, realizando-se em cada etapa apenas o que é necessário para a etapa seguinte.

Gustavus Franklin Swift e Philip Danforth Armour, ambos proprietários de grandes frigoríficos da cidade de Chicago, respectivamente, Swift \& Co. e Armour \& Co., são considerados por muitos pesquisadores os verdadeiros inventores do sistema de produção em série, implantados entre os anos de 1870 e 1880 em seus empreendimentos. As carcaças eram fixadas pelo rabo, desossadas e transportadas aereamente pelas estações de trabalho, num movimento de desmontagem ao contrário da maior parte dos processos em linha.

Em sua autobiografia lançada em 1922 ("My Life and Work"), Henry Ford comenta sobre a inspiração no sistema dos frigoríficos, que o levou a estruturação das linhas de montagem do Ford T. Em Detroit, no ano de 1913, na fábrica Highland Park, Henry Ford, lançava a produção em massa, sistema de montagem em série que revolucionou a indústria automobilística.

Já, nos anos de 1950, a participação dos Engenheiros japoneses Eiji Toyoda e Taiicchi Ohno, o Consultor de Qualidade da Toyota Shingeo Shingo e o Estatístico Edward Deming, juntos levaram ao desenvolvimento do Sistema Toyota de Produção-STP, logo após, batizada como Produção Enxuta. O STP é um modelo de manufatura analisado e aprimorado em cima do fracasso do complexo fabril River Rouge Plant da Ford na cidade de Dearborn, após a dispensa de mais de 7.000 trabalhadores em um curto espaço de tempo. Tal análise desencadeou na Toyota 
Motor Company aumento de velocidade na quantidade de atravessamento do produto (throughput), elevação da produtividade, customização da produção e redução dos desperdícios da fábrica japonesa, conforme, é retratado por James P. Womack (1990) na tradução para o português de "A máquina que mudou o mundo".

Essa linha do tempo, traça as etapas de transformações das formas do andamento da manufatura industrial, o que em Lean se denominou como produção de fluxo contínuo.

Dificuldades encontradas em processos produtivos sequenciados, limitados pelo layout por departamento e composto por amplo mix de produtos fabricados em mesmo período e mesmos postos de trabalho, escondem, em muitos casos, entraves produtivos que podem diminuir a velocidade de atravessamento do produto no fluxo de valor, ou seja, afetando o lead time do produto.

\section{PROCEDIMENTOS METODOLÓGICOS}

A metodologia utilizada, foi empregada de forma exploratória, pois, trata-se do estudo de caso em empresa metalúrgica, onde a abordagem foi feita de forma direta, com coleta de dados in loco, por meio de pesquisa de campo. Também, pode-se informar que é uma pesquisa descritiva, pois, de acordo com Barros e Lehfeld (2000), para coletar dados que caracterizam o processo escolhido, deve existir uma descrição sem interferência no objeto de pesquisa (empresa) por parte do pesquisador.

Segundo Gil (2002), uma pesquisa caracteriza-se como estudo de caso, quando se aprofunda no estudo de um objeto especifico, pois, explora de maneira detalhada tal conhecimento.

A empresa analisada nesse artigo possui mais de quatro décadas de atuação no setor metalúrgico cearense, seu quadro funcional é composto por profissionais experientes e com grande domínio técnico em suas atividades. O maquinário da empresa é moderno e totalmente alinhado as necessidades de fabricação do produto oferecido ao mercado. $\mathrm{O}$ arranjo produtivo é um híbrido de manufatura por projeto e fabricação por lotes, sequenciado por distintos espaços não alinhados. Na carteira de clientes estão grandes construtoras de âmbito local e regional, responsáveis por obras residenciais, industriais e de infraestrutura.

A linha de produção da metalúrgica apresenta-se, conforme, mostra a figura 10.

Figura 10 - Linha de manufatura para montagem de esquadrias de alumínio

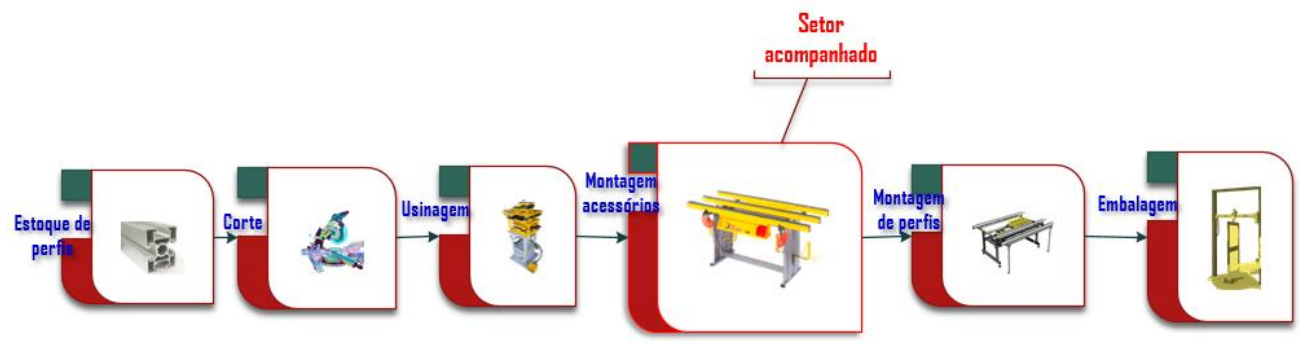

Fonte: Autoria própria (2016). 


\section{APRESENTAÇÃO E DISCUSSÃO DOS RESULTADOS}

Mike Rother (2008), nos leva a questionar um cenário que contenha:

- Produção baseada em grandes lotes, filas apoiadas em layout funcional e seguimentada por departamentos;

- Quadro de produção composto por metas constantemente não atingidas e a existência de oscilações diárias na quantidade produzida diariamente;

- Acúmulos de estoques "amortecedores" variáveis por entre postos de trabalho, pois podem esconder defeitos e desbalanceamentos das cargas de trabalho.

- Quebras de continuidade no andamento do fluxo, causadas por setup's inconsistentes e desnecessários.

Para Spear e Bowen (1999), a filosofia Lean argumenta que produção em lotes pequenos ou unitárias, permitem maior flexibilidade e rápida adaptação às variações de demanda.

Para a criação de um ambiente otimizado e produtivo, entre tantas variáveis, é necessário que se desenvolva também as características para um ambiente propício a um fluxo contínuo. Para isso acontecer é preciso enxergar e questionar se nas células ou linhas de produção da empresa, as informações e os materiais estão fluindo de forma balanceada.

Caminhar no Gemba (lugar real em japonês) e apurar a visão para enxergar desperdícios é uma tarefa que exige do observador, paciência e percepção, o que torna esse momento difícil e desgastante, pois, nem sempre as atividades que não agregam valor se mostram tão evidentes. Mike Rother (2008), descreve que devese aprimorar o olhar sobre suas células produtivas ou linhas e checar se as informações, os materiais e os operadores fluem.

Após acompanhamento das rotinas dos colaboradores, análise do fluxo de materiais e informações, e criação de um esboço do cenário encontrado, foi mapeado o deslocamento dos colaboradores, aplicando uma ferramenta para detectar o percurso e a distância percorrida pelos funcionários da área a ser aplicada as mudanças.

O layout foi analisado para detectar oportunidades de melhoria e permitir a aplicação de um processo de fluxo contínuo. O autor Kostrow (1996), afirma que um layout quando passa por alterações, pode diminuir os riscos de acidentes entre os trabalhadores, contribuir no aumento para eficiência da utilização da mão-deobra disponível, melhorar o moral dos trabalhadores, elevar a comunicação de um posto de trabalho para o outro e otimizar o fluxo.

A empresa acompanhada, possuía uma rotina de produção, em determinados setores, contendo muito desperdício de movimentação entre as atividades operacionais e muito desperdício de transporte entre as estações de trabalho.

Foi acompanhada a rotina de produção no chão de fábrica, analisando o estado atual para entender a realidade que se punha a frente do observador. 
O Mapeamento do Fluxo de Valor (MFV) permite ter uma visão do fluxo portaa-porta no chão de fábrica. Identificar as origens dos desperdícios no processo, expõe a relação entre fluxo de material e informação e também permite enxergar o estado ideal ou o estágio superior ao atual. Após escolher produtos que passam por etapas semelhantes de fabricação e utilizam equipamentos comuns no seu percurso de elaboração, identificou-se a família de produtos a ser trabalhada. Como auxílio, pode-se aplicar uma análise de matriz, conforme, mostra a figura 11 para ajudar na identificação de famílias de produtos.

Figura 11 - Matriz Produto x Processamento

\begin{tabular}{|c|c|c|c|c|c|c|c|c|c|c|}
\hline & \multicolumn{10}{|c|}{ ET APAS DE PROCESSAMENTO } \\
\hline & 1 & 2 & 3 & 4 & 5 & 6 & 7 & 8 & 9 & 10 \\
\hline \multirow{8}{*}{ 鸹 } & 7 & $X$ & & $X$ & & & $X$ & $X$ & $X$ & 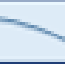 \\
\hline & $\mathbf{x}$ & $x$ & $x$ & $x$ & $x$ & $x$ & $x$ & & $x$ & $x$ \\
\hline & 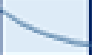 & $x$ & $x$ & $x$ & $x$ & $x$ & $x$ & $x$ & & $x$ \\
\hline & $\mathbf{x}$ & & & & $\mathbf{x}$ & & & $\mathbf{x}$ & $\mathbf{x}$ & $\mathbf{x}$ \\
\hline & $\mathbf{X}$ & & $x$ & $x$ & & $x$ & & $x$ & $x$ & $x$ \\
\hline & & $x$ & $\mathbf{x}$ & $\mathbf{x}$ & $\mathbf{x}$ & & $\mathbf{x}$ & $x$ & & \\
\hline & & $x$ & & & $x$ & & $x$ & & $x$ & $x$ \\
\hline & & & & & & $x$ & & & $x$ & $x$ \\
\hline
\end{tabular}

Fonte: Baseado em Mike Rother e John Shook (2008).

Coletar informações diretamente no processo produtivo e utilizar ícones padrões para o MFV, como mostra alguns exemplos da figura 12, servem para sinalizar os fluxos de materiais e informações do estado atual. Essa prática ajuda a desencadear um montante de idéias que virão a tona, quando o observador estiver diante dos problemas encontrados e que serão parte importante para desenhar as melhorias do MFV do estado futuro.

Figura 12 - Exemplos de ícones de Mapeamento do Fluxo de Valor (MFV)

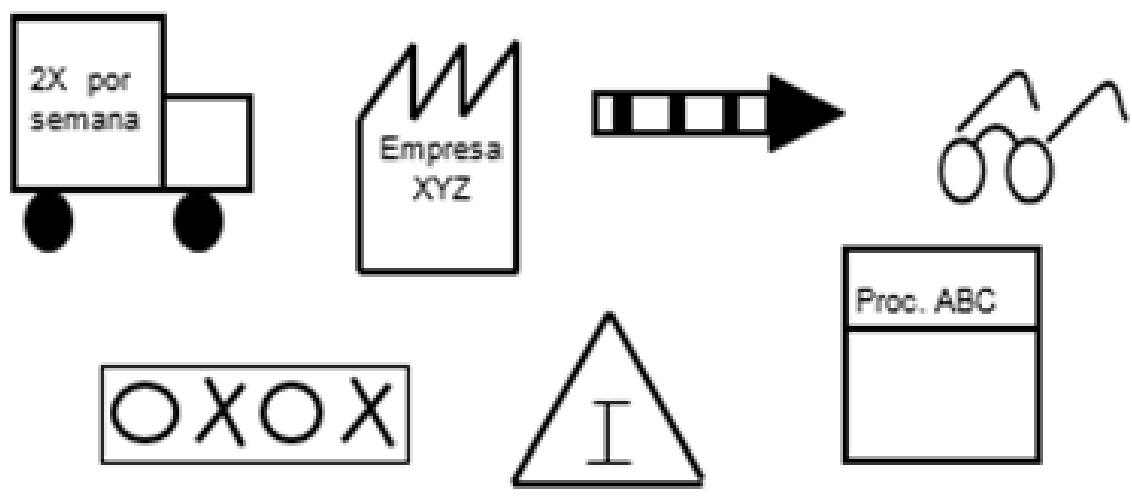

Fonte: Autoria própria (2016). 
Identificar corretamente a percepção de valor do cliente é parte crucial para demandar esforços de mudanças no fluxo de valor correto, pois, do contrário despenderá ações que não agregaram valor nenhum ao consumidor. A elaboração e implementação de um Plano de Ação é importante para nortear uma linha de conduta e atividades, e também como passo em direção da eliminação dos desperdícios detectados.

O estudo do MFV estado atual revelou a área de colocação de acessórios das esquadrias como sendo uma estação de trabalho gargalo. Entre os fatores que o caracterizaram como setor de entrave à produção, estava o fato de haver acúmulo de estoque intermediário, tempo de processamento maior do que nos outros setores e alto nível de deslocamento dos colaboradores entre as estações de trabalho.

Os dados típicos de processo que compõem o MFV da indústria pesquisada, revelaram um Takt Time de 47 minutos. 0 tempo de processamento total para um lote de 10 esquadrias de alumínio em todo o fluxo de valor, tinha um lead time de 533 minutos.

Já, no setor de montagem dos acessários nas esquadrias, o tempo de processamento nesse posto de manufatura era de 150 minutos com um colaborador, fabricando 10 esquadrias (janelas). 0 estoque intermediário, nesse posto de trabalho diariamente formava uma fila, com acúmulo de 111 esquadrias e o deslocamento do colaborador para buscar acessórios no almoxarifado, buscar informações, abastecer sua linha de produção e deixar os seus produtos acabados na estante do próximo setor, acumulavam por cada lote de fabricação, um excesso de movimentação com 117,6 metros percorridos, de forma desnecessária.

A eliminação desses desperdícios abriu como possibilidade, a implementação de uma sistemática de trabalho conhecida na filosofia Lean, como fluxo contínuo, que resultaria após sua aplicação na diminuição do lead time e no aumento da produtividade da empresa analisada.

As figuras 13 e 14, mostram as diferenças antes e depois da alteração do layout do fluxo de materiais entre as estações de trabalho, no setor de montagem de acessórios das esquadrias.

Figura 13 - Layout antes do rearranjo produtivo

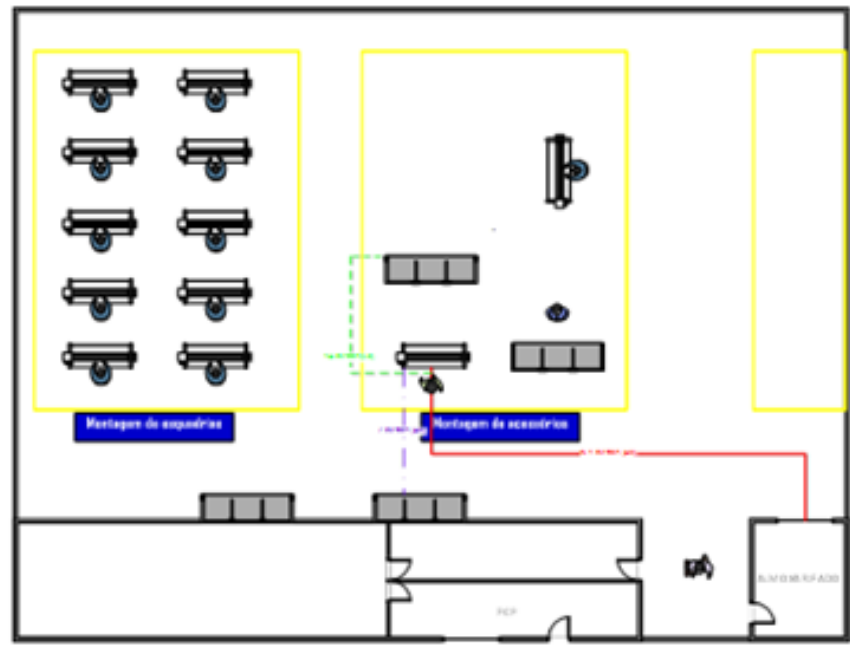


Fonte: Autoria própria (2017).

Figura 14 - pós rearranjo produtivo e uso de abastecedor de linha

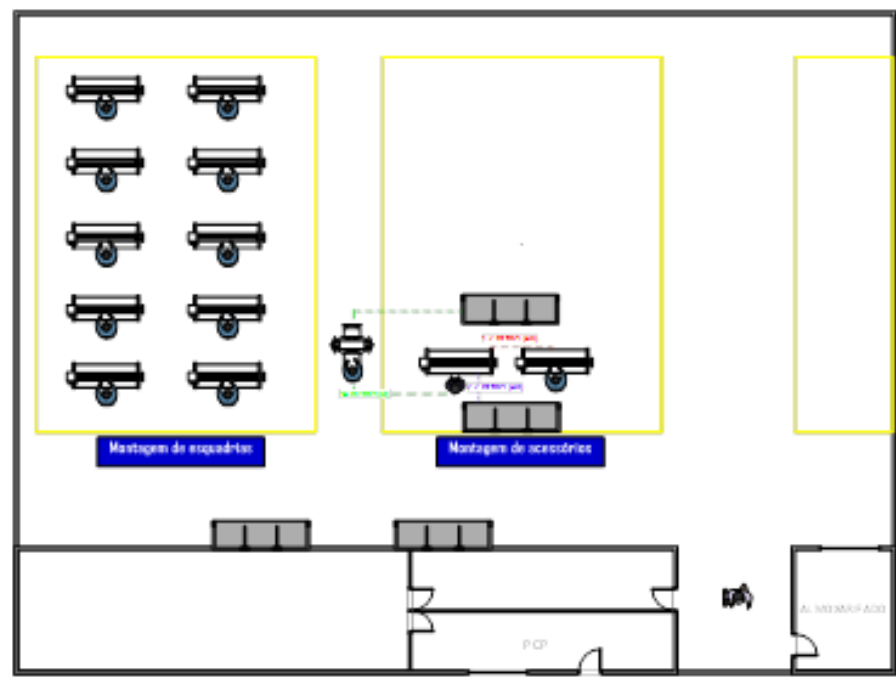

Fonte: Autoria própria (2017).

Aplicando no setor acompanhado, as ações apontadas no MFV estado futuro, ou seja, eliminando os desperdícios lá representados, foram verificados excessos nos deslocamentos entre as estações de trabalho, quebra no andamento do fluxo de materiais e informações, e também, desperdícios de movimentos detectados pelo estudo de cronoanálise.

Diante da situação exposta, foi feito um rearranjo físico na montagem de acessórios das esquadrias, aproximando as estações de trabalho e as estantes de abastecimento. Também, foi acrescentado um abastecedor de linha de produção, o que permitiu que o colaborador da montagem de acessórios não precisasse mais se deslocar em excesso. Após a modificação do layout a movimentação do operador baixou de 176,4 metros para aproximadamente 13,6 metros. Um ganho ergonômico de 92,3\%.

Houve ainda, enxugamento no tempo de ciclo, eliminando todos os elementos de trabalho que não agregavam valor ao cliente, como ilustra a figura 15 , mostrando parte da atividade de colocação de acessórios. Acrescentou-se mais um operador para formação da célula de montagem dos acessórios nas esquadrias, dividindo o ciclo dessa atividade com o objetivo de diminuir a concentração dos elementos de trabalho em uma só pessoa, aumentar a repetibilidade, deixar estável o trabalho dentro de cada ciclo e com isso ganhar velocidade de atravessamento do produto por aquela célula de trabalho. 
Figura 15 - Quadros resumos comparativos para análise de valor agregado
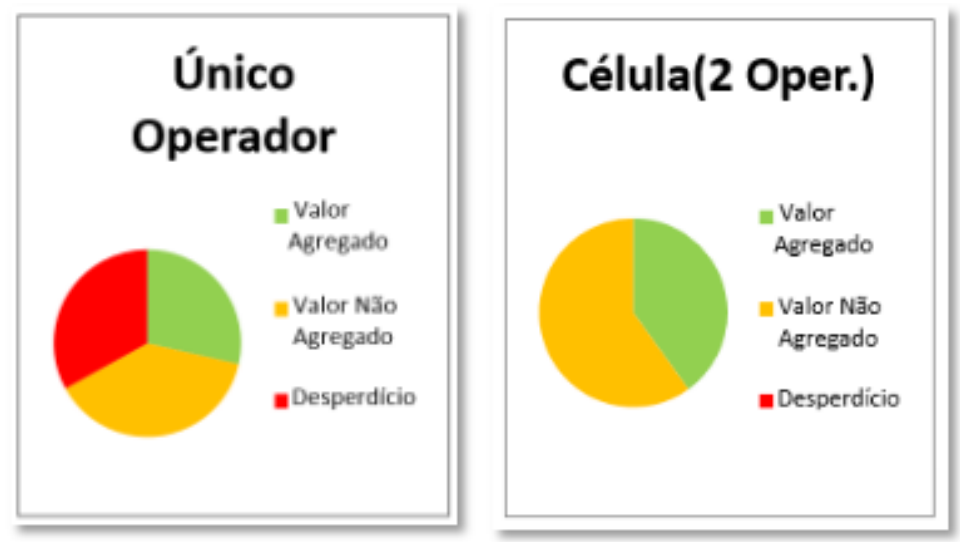

Fonte: Autoria própria (2017).

A figura 16 ilustra a situação anteriormente descrita por meio do gráfico Yamazumi.

Figura 16 - Detalhes do gráfico Yamazumy com comparativo entre Tempo de Ciclo com um operador e célula de montagem com 2 operadores

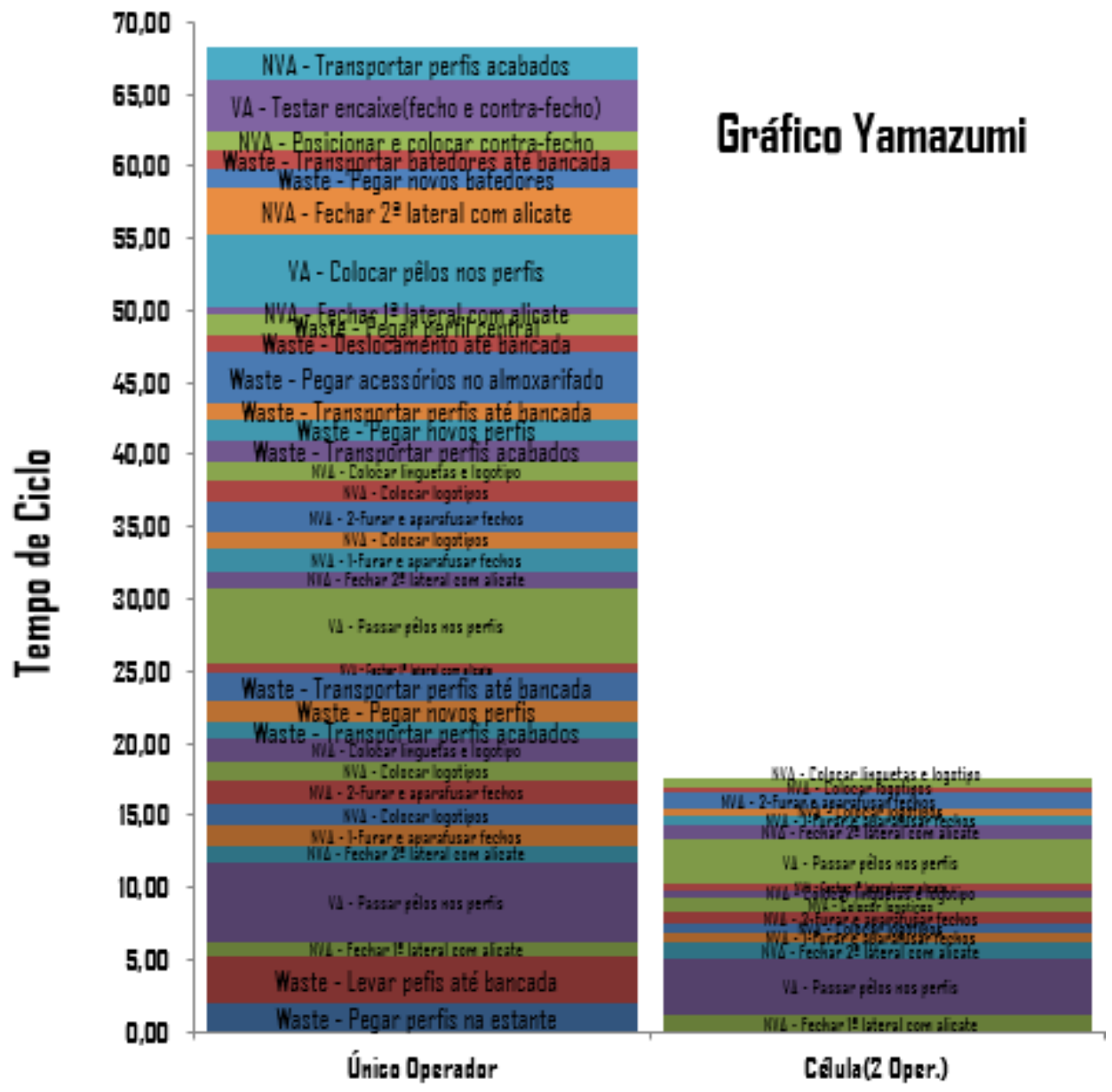

Fonte: Autoria própria (2016). 
Com um operador por estação de trabalho na colocação de acessórios, o tempo utilizado para um lote com 10 esquadrias (janelas) era de 150 minutos, já com o uso de dois operadores e mesmo tamanho de lote, o tempo total de trabalho na célula, baixou para 84 minutos, ou seja, um ganho de produtividade nesse setor de 44\%. Em um turno de 528 minutos de trabalho disponível, no setor estudado, a célula em questão, tem condições de instalar acessórios em aproximadamente 63 janelas por dia.

Com a implantação do rearranjo do layout, enxugamento dos tempos e aplicação do fluxo contínuo, foi possível agregar novos componentes de solução para fortalecer as melhorias no fluxo de valor, tais como, o uso de um kanban "visual" em forma de estante, como mostra a figura 17.

Figura 17 - Estante Kanban "visual" para abastecimento regulado ao setor de montagem de acessórios

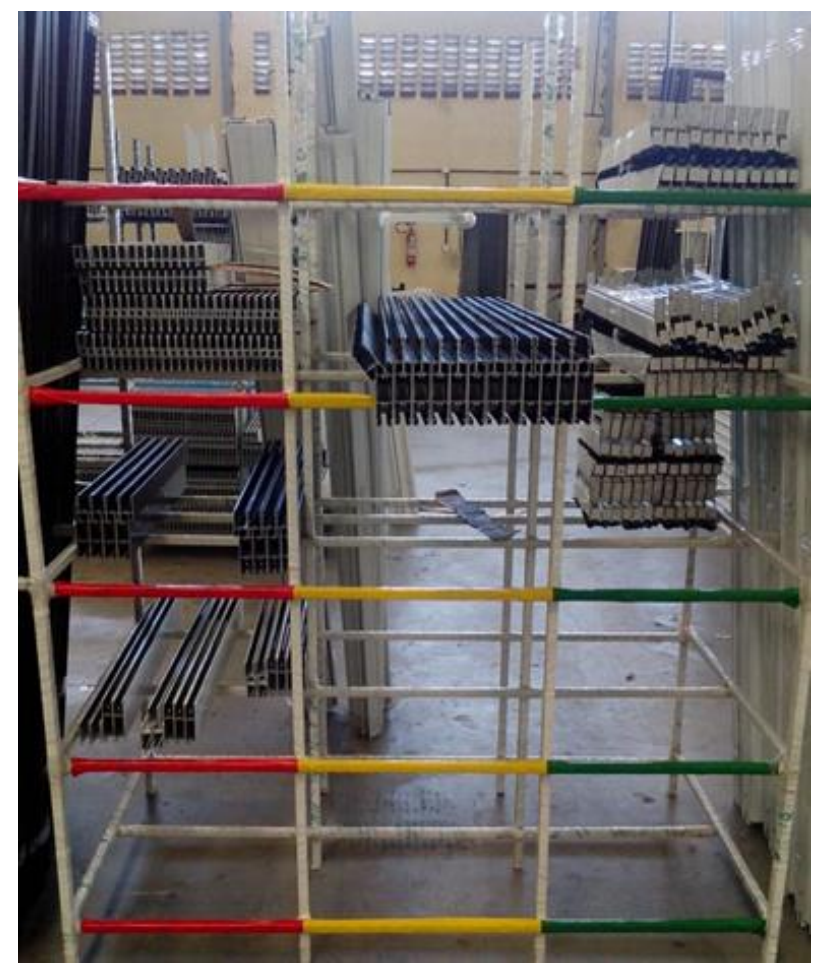

Fonte: Autoria própria (2016).

Com o conhecimento da capacidade de produção do setor de montagem dos acessórios nas esquadrias, foi dimensionado um abastecimento que garante um volume adequado sem excessos de estoques intermediários.

Cada coluna da estante comporta até 40 janelas, perfazendo um total de 120 esquadrias, suprindo uma célula de montagem por mais de um turno ou olhando por outra ótica, uma célula de montagem consumiria em um turno completo, 53\% do total de esquadrias da estante, tendo um pulmão de segurança de aproximadamente 57 janelas ou 478 minutos de produção. As faixas (vermelha, amarela e verde) coladas na estante Kanban da montagem de acessórios, servem para sinalizar ao processo fornecedor, quando a estante precisa ser reabastecida. Também, foi adotado o uso da "linha FIFO" ("first in, first out", "primeiro a entrar, 
primeiro a sair") em conjunto com a adoção do uso de lotes menores, limitados a 10 esquadrias por Ordem de Produção.

No geral, após as mudanças implantadas, o lead time de um lote de 10 esquadrias (janelas) caiu de 533 minutos para 303 minutos de atravessamento entre o ínicio e o final no fluxo de valor, contribuindo assim com uma redução no lead time de $43 \%$.

\section{CONCLUSÕES}

Tem-se ainda um grande número de empresas nacionais, que produzem segundo os modos próprios de constituir sua produção, onde na maioria dos casos, são modelos produtivos historicamente herdados ou copiados pelos fundadores e que ainda não tiveram uma experiência de aplicação prática das ferramentas pertencentes a filosofia Lean Manufacturing. Dentro da filosofia de trabalho Lean, a aplicação do conceito de fluxo contínuo, oportuniza a empresa à implantar ferramentas variadas e que atuam de forma integrada.

Pode-se afirmar, que os ganhos propiciados para a organização estudada foram nos mais variados aspectos, sendo alguns: para o funcionário houve eliminação de desperdícios nos movimentos, com satisfatória melhoria em relação a sua ergonomia; para a empresa ganhos de produtividade, redução do tempo de atravessamento do produto, aumento de valor agregado nas atividades operacionais, com investimento de baixo custo.

Apropriando-se de um olhar sistêmico, a aplicação do conceito de fluxo contínuo vai muito mais além do que a apresentação de uma forma de manufatura. Ela é sim, na verdade, uma forma de mudança comportamental que contribui para o alcance de um objetivo mais amplo, o ganho coletivo de todos os stakeholders envolvidos.

Para o mundo acadêmico, essa pesquisa contribuiu para reflexão sobre um conceito de manufatura ajustável a qualquer modelo de negócio. 


\title{
Data envelopment analysis for princing improvement in a casual dining restaurant
}

\begin{abstract}
There is much talk about Brazil's low productivity in relation to foreign countries, and in the case of organizations, specifically in the industrial sector, this scenario is much more noticeable. Many companies, in order to optimize their results, resort to deploying Lean Philosophy tools, which are constantly looking for waste reduction, and show that involving people is one of the crucial points of success. In this article, we show the application of Lean techniques and their practical and effective results in an industrial manufacturing line, where the objective is to create a productive environment favorable to develop the concept of Continuous Flow, resulting in increased productivity and lead decrease team. The results verified in this implantation proved to be very successful, with great ergonomic improvement for the employees, adoption of a new philosophy of work in series, gains in productivity, elimination of waste, reduction of the time of product crossing through the flow of value and low cost Investment.
\end{abstract}

KEYWORDS: Productivity. Continuous flow. Lean production. Added value. 


\section{REFERÊNCIAS}

BARROS, Aidil J. da Silveira; LEHFELD, Neide A. de Souza. Fundamentos de metodologia, 2000.

CURY, Antonio. Organização e métodos: uma visão holística. Atlas, 2006.

FERRO, José Roberto. A essência da ferramenta "Mapeamento do Fluxo de Valor". Lean Institute Brasil, 2003.

GEORGE, Michael L.; GEORGE, Mike. Lean six sigma for service. New York, NY: McGraw-Hill, 2003.

GHINATO, Paulo. Sistema Toyota de produção: mais do que simplesmente justin-time automação e zero defeitos. EDUCS, 1996.

GIL, Antonio Carlos. Como elaborar projetos de pesquisa. São Paulo, v. 5, p. 61, 2002.

HINES, Peter; TAYLOR, David. Enxugando a empresa: um guia para implementação. São Paulo: IMAM, 2000.

KOSTROW, P. The Facilities Planning Process. CREDIT UNION EXECUTIVE.1996.

MARTINS, Petrônio Garcia; LAUGENI, Fernando Piero. Administração da produção. Saraiva, 2009.

MIKA, Geoffrey. Manufacturing Engineering. Elimante all muda. Dearborn. Proquest Copyright Society Of Manufacturing Engineers. 2001.

OHNO, T.O. Sistema Toyota de Produção - Além da Produção em Larga Escala. Bookman. 1997.

ROCHA, Luiz Oswaldo Leal da. Organização e Métodos, uma Abordagem Prática, 1995. São Paulo: Atlas. 1995.

ROTHER, Mike; SHOOK, John. Aprendendo a enxergar: mapeando o fluxo de valor para agregar valor e eliminar o desperdício: manual de trabalho de uma ferramenta enxuta. Lean Institute Brasil, 2008. 
SHINGO, Shigeo. O Sistema Toyota de Produção do Ponto. Bookman, 1997.

SLACK, Nigel; CHAMBERS, Stuart; JOHNSTON, Robert. Administração da produção. Atlas, 2009.

SPEAR, Steven; BOWEN, H. Kent. Decoding the DNA of the Toyota production system. Harvard business review. 1999.

TURNER, Wayne C. (Ed.). Introduction to industrial and systems engineering. Pearson College Division. 1993.

Recebido: 02 dez. 2016

Aprovado: 14 fev. 2017

DOI: $10.3895 /$ gi.v13n1.5126

Como citar:

LIMA, P. A. M.; LOOS, M. J. Aplicação de fluxo contínuo como contribuição no aumento da produtividade e diminuição do lead time de uma Indústria Metalúrgica. R. Gest. Industr., Ponta Grossa, v. 13, n. 1, p. 99 119, jan./mar. 2017. Disponível em: <https://periodicos.utfpr.edu.br/rgi>. Acesso em: XXX Correspondência:

Paulo André Miranda Lima

Rua Júlio César, 1053, CEP: 60410-505, Jardim América, Fortaleza, CE, Brasil

Direito autoral: Este artigo está licenciado sob os termos da Licença Creative Commons-Atribuição 4.0 Internacional.

(c) (i) 